\title{
HUBUNGAN ANTARA UMUR, POLIHIDRAMNION DENGAN KEJADIAN PERDARAHAN POSTPARTUM DI RSI SULTAN AGUNG SEMARANG
}

\author{
Endang Surani ${ }^{1}$, Sri Wahyuni ${ }^{2}$ \\ Prodi Sarjana dan Profesi Bidan Universitas Islam Sultan Agung Semarang \\ surani@unissula.ac.id \\ sriwahyunimkeb@unissula.ac.id
}

\begin{abstract}
Abstrak
Pendahuluan. Jumlah kasus kematian ibu di Provinsi Jawa Tengah pada tahun 2017 sebanyak 475 kasus, mengalami penurunan dibandingkan jumlah kasus kematian ibu tahun 2016 yang sebanyak 602 kasus. Penyebab kematian ibu yang terbesar kedua di Jawa Tengah sebesar 21,23 $\%$ disebabkan karena perdarahan. Perdarahan post partum merupakan sangat berhubungan dengan kesehatan ibu yang dapat menyebabkan kematian. Data yang didapatkan di RSI Sultan Agung Semarang menunjukkan angka kejadian perdarahan postpartum pada tahun 2016-2017 sebanyak 73 kasus.

Tujuan. Untuk mengetahui hubungan antara umur dan paritas kejadian perdarahan postpartum di RSI Sultan Agung Semarang tahun 2016-2017.

Metode Penelitia. Jenis penelitian ini desktiptif analitik dengan pendekatan case control. Populasi yaitu semua ibu bersalin yang mengalami perdarahan dan tidak perdarahan. Sampel kasus berjumlah 73 responden dengan teknik pengambilan sampel total sampling dan sampel kontrol berjumlah 73 responden dengan teknik pengambilan simple random sampling. Uji statistik yang digunakan Chi-Square, Odds Ratio.

Kesimpulan. Berdasarkan analisis bivariate didapatkan bahwa ada pengaruh antara umur berisiko $(\mathrm{OR}=2,49, \mathrm{p}=0,000)$, polihidramnion $(\mathrm{OR}=0,191, \mathrm{p}=0,000)$ dengan perdarahan postpartum.

Disarankan ibu hamil rutin memeriksakan kehamilannya agar segera terdeteksi apabila mengalami polihidramnion.Disarankan agar para ibu hamil dengan kriteria umur berisiko untuk wapada terhadap kejadian perdarahan post partum.
\end{abstract}

Kata Kunci : Perdarahan post partum, umur, polihidramnion

\begin{abstract}
Background. The number of cases of maternal deaths in Central Java Province in 2017 was 475 cases, a decrease compared to the number of cases of maternal deaths in 2016 which amounted to 602 cases. The second largest cause of maternal death in Central Java was $21.23 \%$ due to bleeding. Post partum hemorrhage is highly related to maternal health which can cause death. The data obtained at Sultan Agung Hospital in Semarang showed that the number of postpartum hemorrhages in 2016-2017 was 73 cases.

Purpose. To determine the relationship between age and parity of the incidence of postpartum hemorrhage at Sultan Agung Hospital in Semarang in 2016-2017.

Methods. This type of research is descriptive analytic with a case control approach. Population is all mothers who have bleeding and no bleeding. Case samples amounted to 73 respondents with total sampling techniques and control samples totaling 73 respondents with simple random sampling. Statistical tests used Chi-Square, Odds Ratio.

Conclusions. Based on bivariate analysis it was found that there was an influence between age at risk $(\mathrm{OR}=2.49, \mathrm{p}=0,000)$ polyhydramnios $(\mathrm{OR}=0.191, \mathrm{p}=0,000)$ with postpartum hemorrhage. It is recommended that pregnant women routinely check their pregnancies
\end{abstract}


to be detected immediately if they experience polyhydramnios. It is recommended that pregnant women with risk age criteria for wapada for post partum bleeding events.

Key Words: Post partum hemorrhage, age, polyhydramnios 
Pendahuluan. Menurut Kemenkes RI (2017) AKI adalah jumlah kematian ibu selama masa kehamilan, persalinan dan nifas yang disebabkan oleh kehamilan, persalinan, dan nifas atau pengelolaannya tetapi bukan karena sebab-sebab lain seperti kecelakaan atau terjatuh di setiap 100.000 kelahiran hidup. AKI pada tahun 2007 sebesar 228 namun pada tahun 2012 menunjukkan peningkatan AKI yang signifikan yaitu menjadi 359 kematian ibu per 100.000 kelahiran hidup. AKI kembali menujukkan penurunan menjadi 305 kematian ibu per 100.000 kelahiran hidup berdasarkan hasil Survei Penduduk Antar Sensus (SUPAS) 2015.

Penyebab kematian ibu yang terbanyak disebabkan karena perdarahan dan faktor dari penyebab perdarahan postpartum yaitu: paritas, umur, jarakhamil kurang dari 2 tahun, dan anemia (Manuaba, 2007).

Perdarahan post partum merupakan salah satu masalah penting karena berhubungan dengan kesehatan ibu yang dapat menyebabkan kematian. Walaupun angka kematian maternal telah menurun dari tahun ke tahun dengan adanya pemeriksaan dan perawatan kehamilan, persalinan di rumah sakit serta adanya fasilitas transfusi darah, namun perdarahan masih tetap merupakan faktor utama dalam kematian ibu. Walaupun seorang perempuan bertahan hidup setelah mengalami pendarahan pasca persalinan, namun ia akan menderita akibat kekurangan darah yang berat (anemia berat) dan akan mengalami masalah kesehatan yang berkepanjangan (Kemenkes, 2015).

Jumlah kasus kematian ibu di Provinsi Jawa Tengah pada tahun 2017 sebanyak 475 kasus, mengalami penurunan dibandingkan jumlah kasus kematian ibu tahun 2016 yang sebanyak 602 kasus. Angka kematian ibu di Kota Semarang pada tahun 2016 terbanyak yaitu sebanyak 32 kasus dan menjadi nomor ke 3 dari 35 di Provinsi Jawa Tengah. Penyebab angka kematian ibu tertinggi kedua di Jawa Tengah adalah dikarenakan perdarahan yaitu sebanyak 21, $23 \%$ (Dinkes Provinsi Jateng, 2018).

Pada tahun 2012 Kementerian Kesehatan meluncurkan program Expanding Maternal and Neonatal Survival (EMAS) dalam rangka menurunkan angka kematian ibu dan neonatal sebesar 25\%. Program EMAS berupaya menurunkan angka kematian ibu dan angka kematian neonatal dengan cara : 1) meningkatkan kualitas pelayanan emergensi obstetri dan bayi baru lahir minimal di 150 Rumah Sakit PONEK dan 300 Puskesmas/Balkesmas PONED) dan 2) memperkuat sistem rujukan yang efisien dan efektif antar puskesmas dan rumah sakit, upaya lain yang dapat dilakukan untuk munurunkan AKI dapat 
dilakukan dengan menjamin agar setiap ibu mampu mengakses pelayanan kesehatan ibu yang berkualitas, seperti pelayanan kesehatan ibu hamil, pertolongan persalinan oleh tenaga kesehatan terlatih di fasilitas pelayanan kesehatan, perawatan pasca persalinan bagi ibu dan bayi, perawatan khusus dan rujukan jika terjadi komplikasi, kemudahan mendapatkan cuti hamil dan melahirkan, dan pelayanan keluarga berencana (Kemenkes RI, 2017).

Peran bidan dalam mencegah perdarahan postpartum yaitu mengurangi faktor resiko dengan melakukan deteksi dini faktor resiko, memberi konseling kepada ibu untuk mengatur umur reproduksi sehat ibu (20-35 tahun), paritas (2-3 anak), jarak kehamilan $\geq 2-5$ tahun, mengendalikan kadar $\mathrm{Hb}$ pada saat kehamilan ( $\geq 11 \mathrm{gr} \%$ ), dan memberikan pemeriksaan ANC minimal 4 kali $(\mathrm{TM} \mathrm{I}=1$ kali, TM II = 1 kali, dan TM $\mathrm{III}=2$ kali), akan tetapi masih banyak ibu hamil yang kurang memanfaatkan pelayanan pra-persalinan, khususnya di daerah pedesaan (Kemenkes RI, 2015).

Rumah Sakit Islam Sultan Agung semarang adalah salah satu rumah sakit swasta terbesar di Kota Semarang dengan akreditasi paripurna dan merupakan rumah sakit syariah pertama di Indonesia. Berdasarkan survey pendauluan yang dilakukan peneliti di rumah sakit Islam sultan agung jumlah persalinan dari 20162017 adalah sejumlah 3217 persalinan. Angka kejadian perdarahan post partum pada tahun tersebut sejumlah 73 kejadian perdarahan post partum dengan penyebab perdarahan post partum terbanyak dikarenakan retensio plasenta. Tujuan Penelitian ini adalah untuk mengetahui hubungan antara umur, polihidramnion dengan kejadian perdarahan post partum di RSI Sultan Agung Semarang.

Metode. Jenis penelitian ini desktiptif analitik dengan pendekatan case control. Populasi yaitu semua ibu bersalin yang mengalami perdarahan dan tidak perdarahan. Sampel kasus berjumlah 73 responden dengan teknik sampling dengan menggunakan total sampling dan sampel kontrol berjumlah 73 responden dengan teknik pengambilan simple random sampling. Uji statistik yang digunakan ChiSquare dan Odds Ratio.Cara pengambilan data dengan menggunakan rekam medis di RSI Sultan Agung Semarang dari tahun 2016- 2017. Etika Penelitian dengan menggunakan Anonimity dan Informed consent.

\section{Hasil Dan Pembahasan}

\section{a. Analisa Univariat}

Tabel 4.1 Distribusi Frekuensi Sampel Berdasarkan Kejadian Perdarahan Postpartum di RSI Sultan Agung

\begin{tabular}{llll}
\hline No & Variabel & Kategori & $\begin{array}{l}\text { Frekuensi } \\
\mathrm{N}=146\end{array}$ \\
\hline 1. & Kejadian & Berisiko $(>500$ & $73(50 \%)$
\end{tabular}




\begin{tabular}{llll}
\hline $\begin{array}{l}\text { Perdarahan } \\
\text { Post Partum }\end{array}$ & cc) & \\
& & $\begin{array}{l}\text { Tidak Berisiko } \\
(<500 \mathrm{cc})\end{array}$ & $73(50 \%)$ \\
2. & Umur & $\begin{array}{l}\text { Berisiko }(<20 \\
\text { tahun atau }>35 \\
\text { tahun })\end{array}$ & $25(17 \%)$ \\
& & $\begin{array}{l}\text { Tidak berisiko } \\
\text { Ya }\end{array}$ & $122(83 \%)$ \\
3. Polihidramni & $86(58,5 \%)$ \\
& on & Tidak & $60(40,8 \%)$ \\
\hline
\end{tabular}

Berdasarkan Tabel 4.1 jumlah sampel kategori yang tidak mengalami perdarahan postpartum sebanyak 73 responden $(50 \%)$ dan kategori yang mengalami perdarahan postpartum sebanyak 73 responden $(50 \%)$. Umur sebanyak 25 responden (17 \%)berisiko, 122 responden (83\%) tidak berisiko. Sebagian besar polihidramnion yaitu sebanyak $86(58,5 \%)$ dan $60(40,8 \%)$ tidak mengalami polihidramnion.

\section{b. Analisa bivariat}

Analisa bivariat pada penelitian ini adalah untuk mengetahui hubungan antara umur dengan kejadian perdarahan post partum, dan untuk mengetahui hubungan antara polihidramnion dengan kejadian perdarahan post partum yang dapat dilihat pada tabel berikut ini:

Tabel 4.2 Hasil Hubungan Antara Umur, Polihidramnion Dengan Kejadian Perdarahan Post Partum

Berdasarkan Tabel 4.2, menunjukkan bahwa terdapat 24 respondenumur berisiko $(<20$ tahun atau $>35$ tahun $)$ mengalami perdarahan post partum, sebanyak 49 responden dengan umur tidak berisiko (2035 tahun) juga mengalami perdarahan post partum. Nilai $\mathrm{p}$ value setelah dianalisismenggunakan chi square sebesar $0,000(<0,05)$. Hal ini menunjukkan bahwa umur mempengaruhi kejadian perdarahan post partum. Untuk analisis menggunakan OR didapatkan nilai OR untuk umur yaitu 2,49 . Ini berarti umur yang $<20$ tahun dan $>$ 35 tahun mempunyai risiko mengalami perdarahan post partum 2,49 kali lebih besar dibandingkan dengan ibu yang berumur 2035 tahun.

Hal ini sejalan dengan Faisal (2008) yang menjelaskan bahwa wanita yang melahirkan anak pada usia dibawah 20 tahun atau lebih dari 35 tahun merupakan faktor risiko terjadinya perdarahan pasca persalinan yang dapat mengakibatkan kematian maternal. Hal ini dikarenakan pada usia dibawah 20 tahun fungsi reproduksi seorang wanita belum berkembang dengan sempurna, sedangkan pada usia diatas 35 tahun fungsi reproduksi seorang wanita sudah mengalami penurunan dibandingkan fungsi reproduksi normal sehingga kemungkinan untuk terjadinya komplikasi

\begin{tabular}{|c|c|c|c|c|c|}
\hline $\begin{array}{l}\mathrm{N} \\
\mathrm{O}\end{array}$ & $\begin{array}{l}\text { Faktor-faktor } \\
\text { yang } \\
\text { mempengaruhi }\end{array}$ & $\begin{array}{l}\text { Perdara } \\
\text { han } \\
\text { (Kelom } \\
\text { pok } \\
\text { Kasus) }\end{array}$ & $\begin{array}{l}\text { Tidak } \\
\text { perdar } \\
\text { ahan } \\
\text { (Kelo } \\
\text { mpok } \\
\text { Kontr } \\
\text { ol) }\end{array}$ & $\begin{array}{l}\mathrm{P} \\
\text { Valu } \\
\mathrm{e}\end{array}$ & OR \\
\hline 1 & $\begin{array}{l}\text { Umur Berisiko } \\
(<20 \text { tahun atau }\end{array}$ & 24 & 0 & $\begin{array}{l}0,00 \\
0\end{array}$ & 2,49 \\
\hline
\end{tabular}

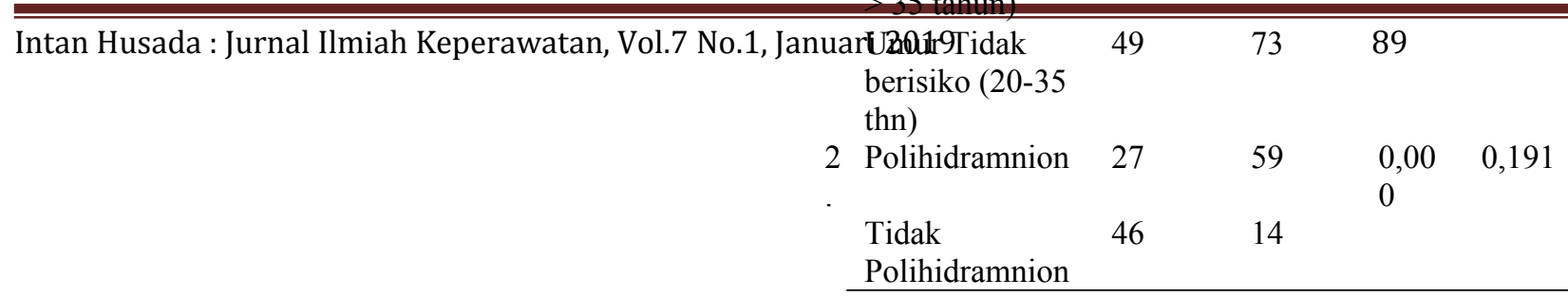


pasca persalinan terutama perdarahan akan lebih besar.

Berdasarkan Tabel 4.2, menunjukkan bahwa terdapat 27 responden yang polihidramnion mengalami perdarahan post partum, Sebanyak 46 responden yang tidak polihidramnion juga mengalami perdarahan post partum. Nilai $\mathrm{p}$ value setelah dianalisis menggunakan chi square sebesar 0,000 $(<0,05)$. Hal ini menunjukkan bahwa polihidramnion mempengaruhi kejadian perdarahan post partum. Untuk analisis menggunakan OR didapatkan nilai OR untuk polihidramnion yaitu 0,191 . Ini berarti ibu bersalin dengan polihidramnion mengalami perdarahan post partum 0,191 kali lebih besar dibandingkan dengan ibu yang tidak polihidramnion.

Saran. Bagi bidan hendaknya lebih meningkatkan pengawasan dalam ANC terutama apabila ditemukan hamil dengan umur yang kategori berisiko karena umur merupakan faktor risiko kejadian perdarahan post partum. Bidan harus selalu melakukan deteksi dini misalnya jika menemukan TFU lebih besar dari usia kehamilannya maka disarankan untuk melakukan USG dikarenakan polihidramnion merupakan faktor risiko dari perdarahan post partum.

Diharapkan peneliti selanjutnya dapat mengembangkan konsep penelitian ini dengan melakukan penelitian faktor selain paritas, umur, anemia, makrosomia, polihidramnion, PEB, induksi oksitosin yang mempengaruhi perdarahan postpartum seperti riwayat persalinan buruk sebelumnya, persalinan dengan tindakan, partus lama, peregangan uterus yang berlebihan dan status gizi.

\section{Daftar Pustaka}

Dinas Kesehatan Provinsi Jawa Tengah. (2017). Profil Kesehatan Provinsi Jawa Tengah. Semarang: Dinas Kesehatan Provinsi Jawa Tengah.

Elmeida, Ayu Mirah W. 2014. Analisis Determinan Perdarahan Post Partum di Rumah Sakit. Jurnal Ilmiah Keperawatan Sai Betik Poltekkes Kemenkes Tanjungkarang Vo 10 No 2.

Faisal. (2008). Perdarahan Pasca Persalinan. http://www.scribd.com/doc/8649214. Diakses pada tanggal 28 Desember 2016

Kemenkes RI. (2015). Profil Kesehatan Indonesia tahun 2014. Jakarta: Kemenkes RI:2015.

Mahmudah S dan Warsiti (2010). Hubungan riwayat pre eklampsia dengan kejdian perdarahan post partum di RSUP dr, Sardjito Yogyakarta 2010. http://digilib.unisayogya.ac.id/1612/1/ Naskah\%20Publikasi.pdf

Manuaba, I.B.G.F. (2007). Pengantar Kuliah Obstetri. Jakarta: EGC Prawirohardjo, Sarwono. (2010). Ilmu Kebidanan. Jakarta: Yayasan Bina Pustaka 
Saifuddin, A.B. (2009). Panduan Praktis Pelayanan Kesehatan Maternal dan Neonatal. Jakarta:EGC

Sembiring.(2010). Hubungan Anemia Dalam Kehamilan Dengan Kejadian Perdarahan Post Partum Di RSUP H. Adam Malik Medan.Jurnal D III Kebidanan Mutiara Indonesia.

Satriyandari, Hariyati. 2017. Faktor-faktor yang mempengaruhi kejadian perdarahan post partum. Jurnal kebidanan dan Keperawatan Universitas Aisyiyah Yogyakarta.Vol 1 No 1 tahun 2017.https://ejournal.unisayogya.ac.id/ ejournal/index.php/JHeS/article/view/ $\underline{185}$

Winkjosastro.(2008). Ilmu

Kebidanan.Jakarta : YBPSP 
